\title{
Hypoxia Inhibits Expression of Prolactin and Secretion of Cathepsin-D by the GH4C1 Pituitary Adenoma Cell Line
}

\author{
Gabriela Cosío, Michael C. Jeziorski, Fernando López-Barrera, \\ Gonzalo Martínez de la Escalera, and Carmen Clapp
}

Neurobiology Institute, National Autonomous University of Mexico, Campus UNAM-Juriquilla, Queretaro, Qro, Mexico

\begin{abstract}
SUMMARY: Diminished oxygen concentration within growing tumors may stimulate neovascularization by inducing both up-regulation of angiogenic factors and down-regulation of antiangiogenic agents. A potentially important molecule in the growth of pituitary adenomas is prolactin (PRL), which can be cleaved by cathepsin-D to yield a 16-kDa form (16K-PRL) with potent antiangiogenic effects. We examined the expression of PRL in cultured GH4C1 pituitary adenoma cells after exposure to hypoxia ( $0.1 \%$ oxygen) for periods of 12 to 36 hours. In contrast to increased expression of the angiogenic factor vascular endothelial growth factor in hypoxic cells, PRL mRNA and levels of intracellular and secreted PRL were significantly reduced under hypoxia. The reduction was not attributable to a general suppression of either transcription or protein synthesis. Although $16 \mathrm{~K}-\mathrm{PRL}$ was not evident in conditioned medium at physiologic $\mathrm{pH}$, lowering the $\mathrm{pH}$ to mimic the acidic tumor microenvironment resulted in generation of 16K-PRL, which was sharply reduced in medium drawn from hypoxic cells. Production of $16 \mathrm{~K}-\mathrm{PRL}$ was blocked by the cathepsin-D inhibitor pepstatin-A, and the reduced 16K-PRL formation in hypoxic-conditioned medium correlated with a decrease in secretion of cathepsin-D and its precursor, procathepsin-D. Thus, hypoxia acts upon GH4C1 cells to increase vascular endothelial growth factor expression, decrease PRL synthesis, and suppress conversion of PRL to 16K-PRL via inhibition of cathepsin-D proteolysis. These mechanisms may act in concert to stimulate angiogenesis in prolactinomas. (Lab Invest 2003, 83:1627-1636).
\end{abstract}

$$
T
$$
he growth of pituitary adenomas, as of all tumors, depends on adequate vascularization once tumors have grown beyond a few millimeters in size (Folkman, 1990). However, in contrast to other tumors, pituitary adenomas are less vascularized than the normal tissue (Jugenburg et al, 1995; Schechter, 1972; Turner et al, 2000a). Because an adequate blood supply enables tumor cells to proliferate further or metastasize to another organ, the reduced vascularization of pituitary adenomas suggests that inhibition of angiogenesis in these tumors plays a role in their characteristic slow growth and failure to reach the carcinoma stage (Jugenburg et al, 1995; Turner et al, 2000a, 2000b; Vidal et al, 2000a). Among pituitary tumors, those secreting prolactin (PRL) occur most frequently. They range from microprolactinomas,

DOI: 10.1097/01.LAB.0000098429.59348.36

Received August 27, 2003.

This work was supported by Grants 36041-N and 34309-N from the National Council of Science and Technology of Mexico (CONACYT), Grants PUIS, IN227502, and IN221702 from the National Autonomous University of Mexico, and Grant 55000595 from the Howard Hughes Medical Institute.

Address reprint requests to: Dr. C. Clapp, Instituto de Neurobiologia, Universidad Nacional Autónoma de México, Campus UNAM-Juriquilla, Apartado Postal 1-1141, Querétaro, Qro., Mexico 76001. E-mail: clapp@servidor.unam.mx which rarely progress in size, to large extracellular macroprolactinomas that may invade local tissues (Cunnah and Besser, 1991). These differences fit with the observation that the vascular density of macroprolactinomas is significantly greater than that of microprolactinomas (Turner et al, 2000a) and further suggest that inhibitors of angiogenesis might influence the phenotype and behavior of these tumors.

One putative inhibitor of angiogenesis in the pituitary gland is a fragment of PRL. The full-length 23-kDa PRL molecule can be posttranslationally processed by proteolytic cleavage to a $16-\mathrm{kDa}$ form (16K-PRL) that has unique antiangiogenic actions not shared with the full-length molecule (Clapp et al, 1993; Corbacho et al, 2002). 16K-PRL can be generated in the anterior pituitary gland of rats (Shah and Hymer, 1989; Torner et al, 1995), mice (Sinha and Gilligan, 1984), and humans (Pellegrini et al, 1988; Sinha et al, 1985; Warner et al, 1993) and acts as a potent inhibitor of angiogenesis in vivo and in vitro, inhibiting endothelial cell proliferation (Clapp et al, 1993) and stimulating type 1 plasminogen activator inhibitor expression (Lee et al, 1998) and endothelial cell apoptosis (Martini et al, 2000). Inhibition of angiogenesis by 16K-PRL would be critically influenced by the availability of both the parent molecule (PRL) and the protease responsible for processing PRL. Various lines of evidence suggest that the protease is cathepsin-D, a ubiquitous acidic-aspartyl endopro- 
teinase in lysosomes (Baldocchi et al, 1993; Corbacho et al, 2002). Cathepsin-D is secreted by tumor cells (Morikawa et al, 2000; Rochefort et al, 1990) and is thought to be associated with tumor progression (Berchem et al, 2002; Rochefort et al, 2000).

Hypoxia, a common feature of solid tumors, results from insufficient blood perfusion and oxygen consumption rates that exceed oxygen supply (Hockel and Vaupel, 2001). Hypoxic conditions affect the expression of a well-characterized battery of genes that help cells cope with low oxygen concentrations, including the up-regulation of several genes encoding angiogenic factors and the down-regulation of angiogenesis inhibitors (Richard et al, 1999; Tenan et al, 2000). Because 16K-PRL is antiangiogenic, we speculated that a hypoxic milieu could reduce the generation of 16K-PRL in pituitary tumor cells, either by affecting expression of the parent $P R L$ form or by modulating the availability of the protease responsible for processing PRL. Lowering 16K-PRL may be one of the mechanisms determining the increased vascularization of macroprolactinomas versus microprolactinomas and other pituitary adenomas. In the present study, we examined the effects of hypoxia on PRL gene expression and cathepsin-D levels in the rat GH4C1 pituitary adenoma cell line.

\section{Results}

The experimental protocol used to study hypoxia involved exposure of GH4C1 cells to $0.1 \%$ oxygen for periods of up to 36 hours. GH4C1 cells were found to be relatively resistant to hypoxia-induced reduction of cell viability. No morphologic change was seen in GH4C1 cells at any of the time points (not shown), and the number of adherent cells was constant for up to 24 hours of hypoxia (Fig. 1A). By 36 hours there was a significant $(p<0.05)$ reduction in the number of adherent cells; however, for the cells that remained attached, hypoxic treatment for up to 36 hours induced no discernible loss of viability (Fig. 1B).

Because low concentrations of oxygen have previously been reported to stimulate the expression of angiogenic factors such as vascular endothelial growth factor (VEGF) in tumor cells (Minchenko et al, 1994; Shweiki et al, 1992) and because the GH3 cell line, parental to $\mathrm{GH} 4 \mathrm{C} 1$ cells, expresses VEGF (Lohrer et al, 2001; Ochoa et al, 2000; Vidal et al, 2000b), we used RT-PCR to assay transcription of several forms of VEGF in GH4C1 cells in response to hypoxia. Transcription of both the 164 and 120 amino acid variants of VEGF was elevated in $\mathrm{GH} 4 \mathrm{C} 1$ cells after hypoxic treatment for 12 hours (Fig. 2A), and this increase persisted for at least 24 hours. At each time point, the increase in the mRNA encoding for VEGF164 was about 2-fold and that of VEGF120 was about 1.5-fold (Fig. 2B). No band corresponding to a VEGF188 transcript was detected.

In contrast to VEGF, PRL mRNA levels were significantly decreased under the same conditions. Northern blots showed that PRL mRNA was reduced in $\mathrm{GH} 4 \mathrm{C} 1$ cells after 12 hours of exposure to hypoxia.
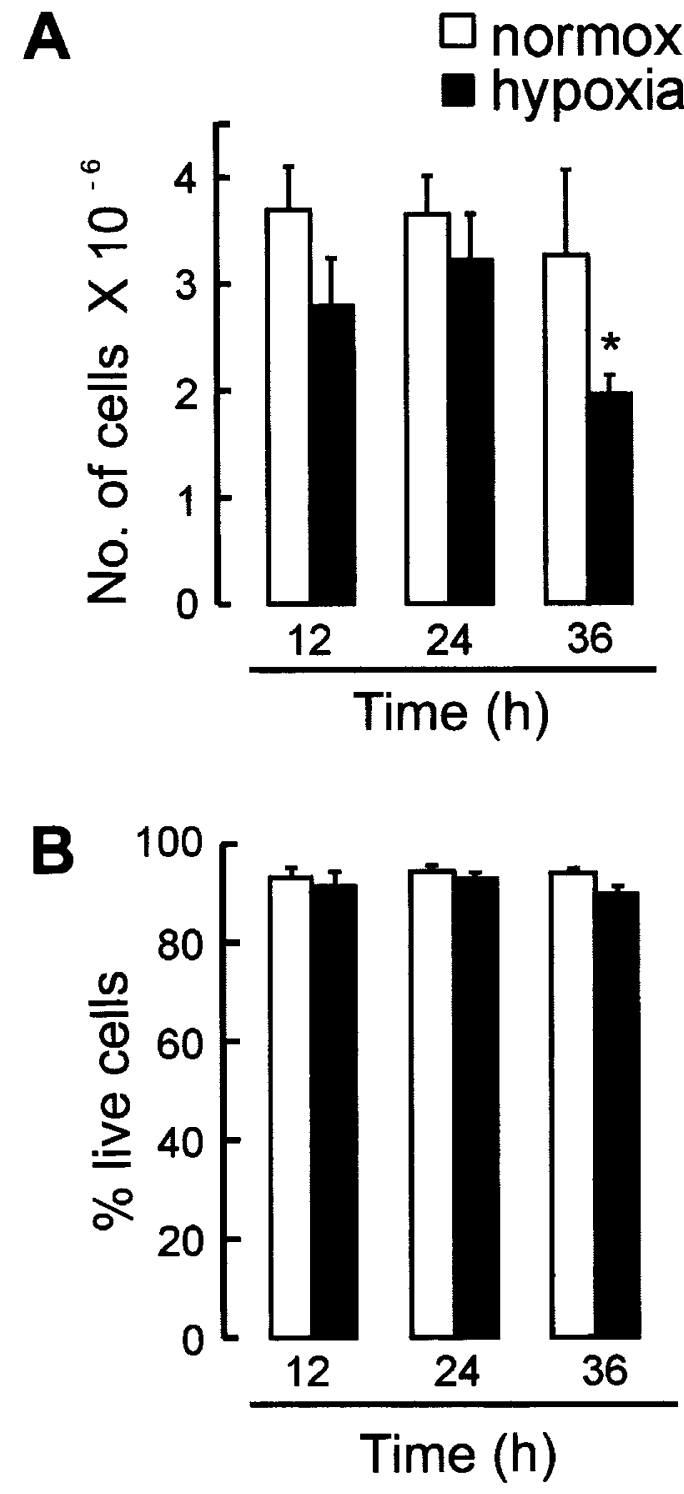

Figure 1

Effect of hypoxia on cell number (A) and viability (B). Confluent GH4C1 cells were cultured in normoxic or hypoxic conditions for 12 to 36 hours. Adherent cells were lifted by trypsin treatment and counted by hemocytometer, and the percentage of viable cells was determined by trypan blue exclusion. Data are mean values \pm SEM of three independent experiments. ${ }^{\star} p<0.05$ vs corresponding normoxic value.

The decrease was more apparent with longer treatments, because the PRL transcript accumulated in cells under normoxic conditions but declined in hypoxic cells (Fig. 3A). After 36 hours of hypoxia, PRL mRNA was reduced by approximately $80 \%$ (Fig. 3B). Reduction of transcription was not a general phenomenon in hypoxic $\mathrm{GH} 4 \mathrm{C} 1$ cells, because rehybridizing with a probe for $\beta$-actin showed no alteration of expression of this constitutive gene under hypoxia (Fig. 3A).

The decrease in transcription of the PRL gene was accompanied by a reduction in levels of the protein. Western blotting of $\mathrm{GH} 4 \mathrm{C} 1$ homogenates showed decreased PRL levels after 12 to 36 hours of hypoxic treatment (Fig. 4A). As with mRNA levels, intracellular 
A

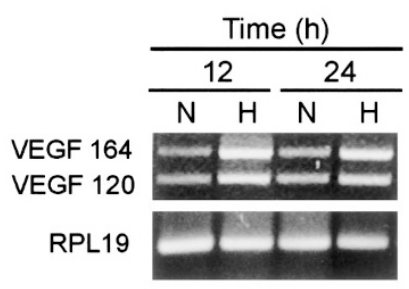

B
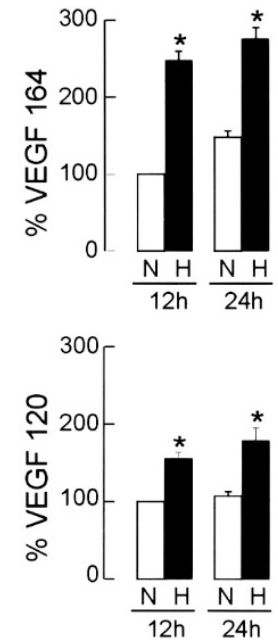

Figure 2.

Hypoxia-induced up-regulation of vascular endothelial growth factor (VEGF) expression. A, VEGF mRNAs encoding isoforms 164 (563 bp) and 120 (431 bp) were analyzed by RT-PCR performed on total RNA extracted from GH4C1 cells cultured for 12 or 24 hours under normoxic $(M)$ or hypoxic $(H)$ conditions. Amplification of the housekeeping gene ribosomal protein L19 was used as a control. B, VEGF mRNA values were evaluated densitometrically and normalized with respect to the 12-hour normoxia value. Data are mean \pm SEM of three independent experiments. ${ }^{*} p<0.05$ with respect to the corresponding normoxic value.

PRL continued to accumulate when oxygen concentration was normal but declined under hypoxia. In contrast, levels of $\beta$-actin remained unaltered by the oxygen status of the culture. Secreted PRL was also examined and found to rise under normoxic conditions, increasing more than 2-fold between 12 and 36 hours of incubation (Fig. 4B). In comparison, hypoxic cells secreted less PRL after 12 hours of treatment, and PRL levels at subsequent time points were consistently lower than in normoxic cells. Furthermore, the rate of accumulation of secreted PRL was lower under hypoxia than under normoxia. These findings were confirmed by ELISA determinations showing a significant $(p<0.05) 2$-fold reduction of secreted PRL under hypoxia $\left(83.5 \pm 6.1\right.$ vs $43.3 \pm 6.6 \mu \mathrm{g} / 10^{6}$ cells for 24 hours of normoxia vs hypoxia, respectively). To examine whether reduction of PRL secretion could be a general phenomenon for all proteins secreted by GH4C1 cells, we compared levels of secreted proteins under hypoxia and normoxia by silver staining (Fig. $4 \mathrm{C}$ ). Levels of the majority of secreted proteins were not altered under hypoxia.

Although the polyclonal antibody used in these experiments binds to several forms of PRL, including the 23-kDa and 16-kDa variants, no product other than 23K-PRL was detected in either GH4C1 cell homogenates or conditioned media. Because cathepsin-D, the presumed PRL-processing enzyme, acts at acidic $\mathrm{pH}$ and because the extracellular $\mathrm{pH}$ of tumors is acidic (Stubbs et al, 2000), we speculated that $16 \mathrm{~K}-\mathrm{PRL}$ could be generated extracellularly via cathepsin-D secreted by tumor cells into an acidic microenvironment. To determine whether the proteolytic activity responsible for generation of $16 \mathrm{~K}-\mathrm{PRL}$ was present in the conditioned medium of $\mathrm{GH} 4 \mathrm{C} 1$
A Time $(\mathrm{h})$
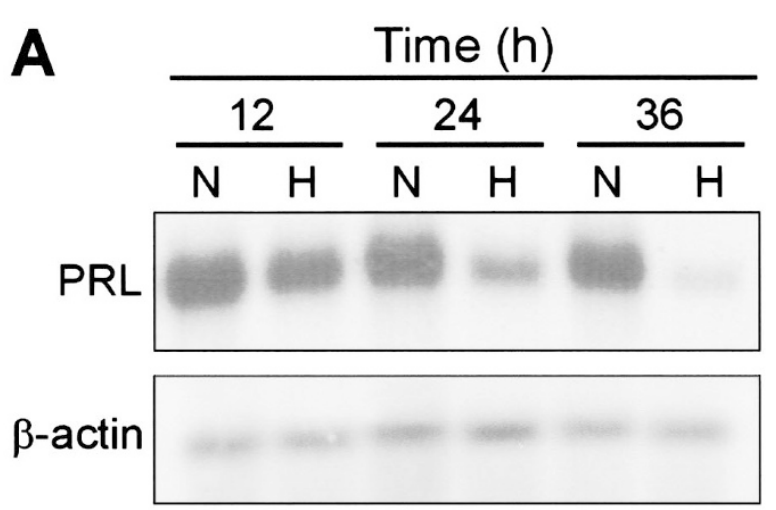

B

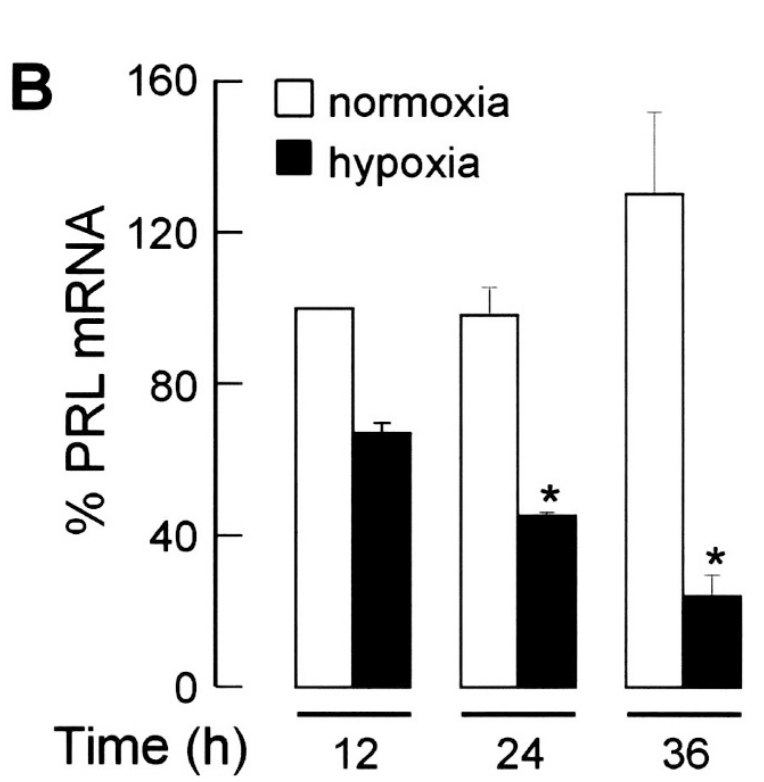

Figure 3.

Hypoxia-induced down-regulation of prolactin (PRL) mRNA. A, Northern blot for PRL mRNA and $\beta$-actin in GH4C1 cells exposed for 12 to 36 hours to normoxia $(M)$ or hypoxia $(H)$. B, PRL mRNA values were quantified densitometrically and normalized with respect to the 12-hour normoxia value. Data are mean \pm SEM of three independent experiments. ${ }^{*} p<0.05$ with respect to the corresponding normoxic value.

cells, medium drawn from cells after 24 hours of normoxia or hypoxia was incubated at $\mathrm{pH} 5.6$ for 24 hours at $37^{\circ} \mathrm{C}$, and proteolysis of PRL in the medium was evaluated by Western blots. When conditioned medium was exposed to low $\mathrm{pH}$, a second immunoreactive product was seen in addition to $P R L$ that corresponded in size to $16 \mathrm{~K}-\mathrm{PRL}$ (Fig. 5A). The concentration of the $16-\mathrm{kDa}$ product relative to that of 23K-PRL was 4-fold lower in medium drawn from hypoxic cells (Fig. 5B). Generation of the $16-\mathrm{kDa}$ product seemed to be attributable to a protease released by the cells, because no 16K-PRL was evident when the conditioned medium was heat inactivated (not shown) or when a $23 \mathrm{~K}-\mathrm{PRL}$ standard was incubated at a low pH in nonconditioned medium (Fig. $5 A)$.

In support of cathepsin-D being the responsible protease, the generation of the $16 \mathrm{~K}-\mathrm{PRL}$ at acidic $\mathrm{pH}$ was inhibited by the cathepsin-D inhibitor pepstatin-A (Fig. 5A). We examined the acidified medium from 
A. Intracellular PRL
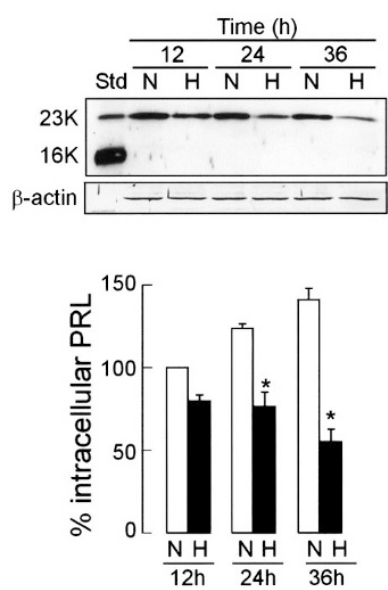

B. Secreted PRL
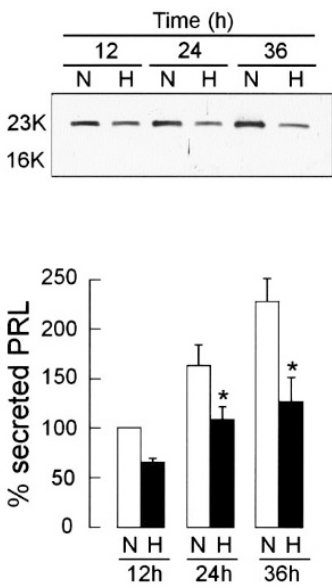

\section{Total secreted protein}

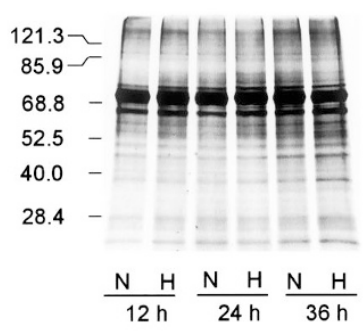

Figure 4.

Hypoxia-induced inhibition of intracellular and secreted PRL. PRL was analyzed by Western blots in homogenates (A) and conditioned media (B) of GH4C1 cells exposed to normoxia $(M)$ or hypoxia $(H)$ for 12 to 36 hours. Blots from homogenates were reblotted with anti- $\beta$-actin antibodies $(A)$. PRL bands were evaluated densitometrically and normalized with respect to the 12-hour normoxia value. Data are mean \pm sem from three independent experiments. ${ }^{*} p<0.05$ with respect to the corresponding normoxic value. C, Silver staining of secreted proteins from GH4C1 cells exposed to normoxia $(M)$ or hypoxia $(H)$ for 12 to 36 hours. Proteins from conditioned medium drawn from $6.5 \times 10^{4}$ cells were precipitated with trichloroacetic acid and loaded. The major protein band of $70 \mathrm{kDa}$ is a medium constituent, and none of the other proteins were detected in nonconditioned medium processed in the same way as GH4C1-conditioned medium.

GH4C1 cells by immunoblotting to detect cathepsin-D isoforms and determined whether their levels decreased under hypoxic conditions. Procathepsin-D, the 52-kDa precursor of cathepsin-D, and mature cathepsin-D (33 kDa) were detected in $\mathrm{GH} 4 \mathrm{C} 1$ conditioned medium (Fig. 6A) but not in nonconditioned medium (not shown). The concentration of both forms of the enzyme increased with time but was lower in hypoxic cells at the two times measured (Fig. 6B).

\section{Discussion}

Cells exposed to low oxygen levels adapt by altering the transcription of numerous genes involved either in decreasing cellular oxygen consumption or in increasing oxygen availability to the tissues (Bunn and Poyton, 1996). Angiogenesis is one major mechanism that increases oxygen availability, and hypoxia upregulates angiogenesis activators and down-regulates inhibitors. Because 16K-PRL, a potent inhibitor of angiogenesis, is derived from PRL by proteolysis, we reasoned that hypoxia might down-regulate $\mathrm{PRL}$ gene expression in pituitary lactotrophs. Here, we report that PRL production, as well as its cathepsin-Dmediated conversion to 16K-PRL, are decreased by exposure of a pituitary tumor cell line to low oxygen.

We demonstrate that hypoxia reduces the expression of PRL mRNA and protein in the GH4C1 lactrotoph cell line. In contrast to PRL, VEGF164 and VEGF120 mRNA were up-regulated by hypoxia, demonstrating the ability of $\mathrm{GH} 4 \mathrm{C} 1$ cells to respond to low oxygen tension via the transcription of hypoxiainducible genes. VEGF164 and 120 are secreted isoforms of VEGF that are active in angiogenesis (Enholm et al, 1997), and their expression is increased in several tumor cell lines in response to hypoxia (Minchenko et al, 1994; Shweiki et al, 1992). Thus, the

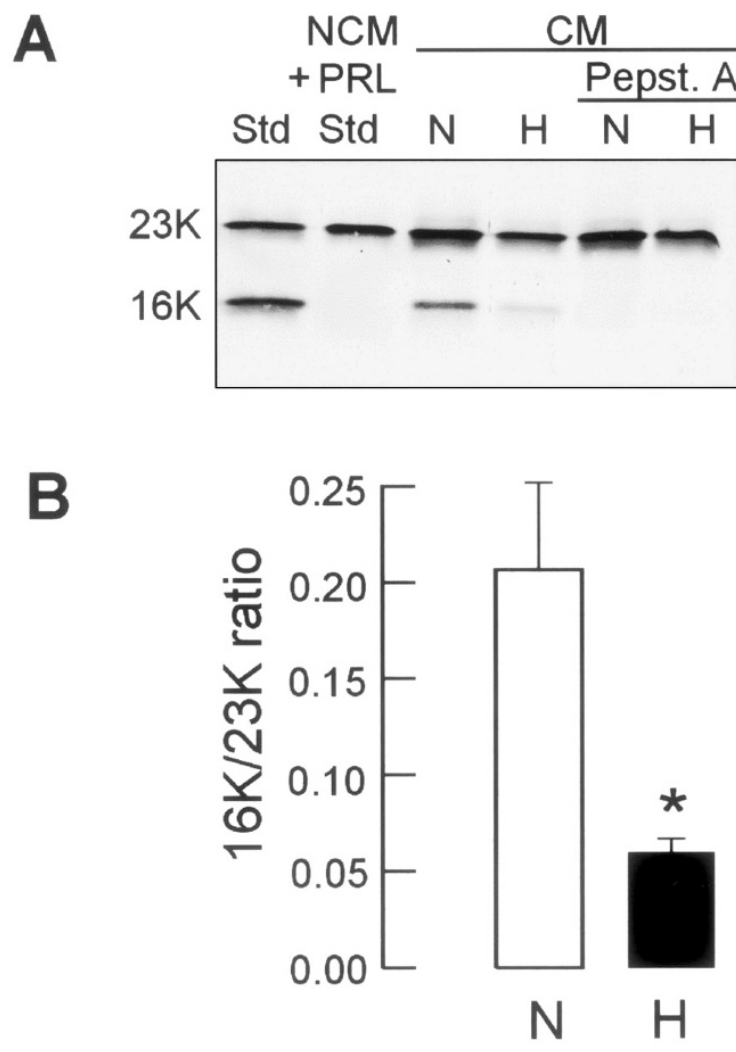

Figure 5.

Hypoxia-induced inhibition of PRL-cleaving activity. A, The conditioned medium (CM) of GH4C1 cells exposed to normoxia $(M)$ or hypoxia $(H)$ for 24 hours was acidified ( $\mathrm{pH} 5.6$ ), incubated at $37^{\circ} \mathrm{C}$ for 24 hours in the absence or presence of pepstatin-A (Pepst.A, $1 \mu \mathrm{M})$, and analyzed by Western blot. Acidified nonconditioned medium (NCM) was incubated with a purified 23K-PRL standard under the same conditions as CM. B, PRL bands were evaluated densitometrically and expressed as the ratio of $16 \mathrm{~K}-\mathrm{PRL}$ to $23 \mathrm{~K}$ PRL. Ratios are mean \pm SEM from three independent experiments. ${ }^{*} p<0.05$ with respect to the corresponding normoxic value. 
A
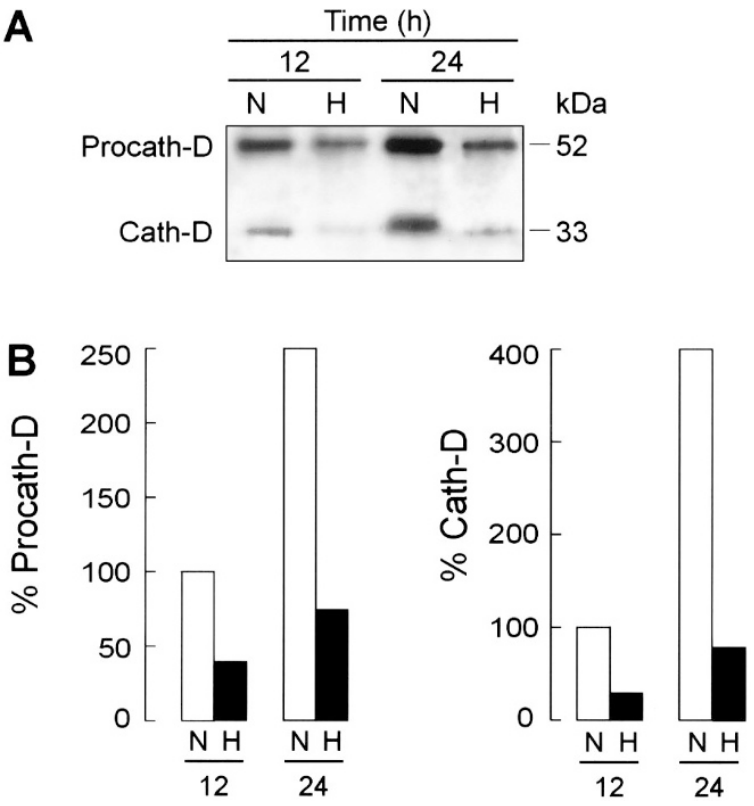

Figure 6.

Hypoxia-induced inhibition of secretion of cathepsin-D isoforms. A, Western blot analysis of pro-cathepsin-D (Procath-D) and cathepsin-D (Cath-D) in acidified ( $\mathrm{pH}$ 5.6) conditioned medium from GH4C1 cultures exposed to normoxia $(M)$ or hypoxia $(H)$ for 12 or 24 hours. B, Protein bands were evaluated densitometrically and normalized with respect to the 12-hour value under normoxia.

up-regulation of VEGF by hypoxia in $\mathrm{GH} 4 \mathrm{C} 1$ cells supports the notion that hypoxia is an important factor for the progression of PRL-secreting adenomas. In this regard, VEGF levels increase in the pituitary gland during the development of estrogen-induced prolactinomas (Banerjee et al, 1997), and both VEGF164 and VEGF120 are up-regulated by estrogens in the pituitary gland and in the GH3 lactotroph cell line (Ochoa et al, 2000).

Hypoxia did not inhibit PRL mRNA and protein through toxic effects on $\mathrm{GH} 4 \mathrm{C} 1$ cells. Morphologically, the cells appeared unaffected by the extreme levels of oxygen deprivation used in this study, which recreate near-zero tissue oxygen levels measured in experimental models of wound repair (Niinikoski et al, 1972) or in areas within solid tumors (Hockel and Vaupel, 2001). Functionally, there was no difference in the number of GH4C1 cells for up to 24 hours of hypoxia, and the viability of attached cells remained constant at all times. Prolonged exposure to hypoxia can induce programmed cell death in some mammalian cells (Graeber et al, 1996) but not in others (Berk et al, 1999; Lou et al, 1997). Resistance to hypoxiainduced apoptosis seems particularly important among tumor cells, in which some studies claim that by inducing apoptosis, hypoxia may select for cells with defective apoptotic regulators such as p53 (Graeber et al, 1996) and a more aggressive phenotype (Brizel et al, 1996).

Likewise, hypoxia did not reduce PRL levels in GH4C1 cells by nonspecific suppression of protein synthesis and secretion. The mRNA levels of a constitutive protein ( $\beta$-actin) and the levels of the majority of secreted proteins remained unaltered under hypoxic conditions. Hypoxia exposure for 12 to 24 hours exerts no effect on total protein levels in some cell types (Tenan et al, 2000), although prolonged exposures generally decrease the rate of total protein synthesis (Hochachka et al, 1996).

The functional implication of hypoxia-induced inhibition of PRL expression is unclear. Reduction in tissue oxygen concentration is usually associated with numerous cellular, local, and systemic adaptive responses. Reduction in PRL production by pituitary cells could represent a systemic adaptive response to hypoxia. In fact, exposure to hypoxia does affect systemic PRL concentrations in rats (Zhang and Du, 2000) and humans (Bouissou et al, 1987). Placing male rats for 2 hours in hypobaric chambers simulating an altitude of $7 \mathrm{~km}$ (7.2\% oxygen) reduced the content of $\mathrm{PRL}$ in the pituitary gland and in the circulation (Zhang and $\mathrm{Du}, 2000)$. Similarly, acute exposure to hypoxia (14.5\% oxygen) inhibits the increase in blood PRL induced by maximal exercise in human subjects (Bouissou et al, 1987). At the whole body level, the inhibitory effect of acute hypoxia upon PRL is not entirely unexpected. Hypoxia increases expression of the gene encoding tyrosine hydroxylase, the rate-limiting enzyme in the synthesis of dopamine, which is the main inhibitor of pituitary PRL synthesis and secretion (Czyzyk-krzeska et al, 1994). Furthermore, the effects of blood oxygen partial pressure on PRL levels may be part of a stress-induced response. Hypoxia can activate the hypothalamo-pituitary-adrenocorticoid axis (Chen and Du, 1996), inhibit immune function (Bai et al, 1997), and suppress body growth and reproduction (Du and $\mathrm{Li}$, 1982; Moromisato et al, 1999; Yang et al, 1995).

Nevertheless, here we show that hypoxia acts directly on pituitary lactotrophs to inhibit PRL expression. Although further studies are underway to localize hypoxia-responsive motifs repressing PRL promoter function, our current results suggest that inhibition of $\mathrm{PRL}$ expression by a reduction in oxygen supply could have an impact at the local pituitary level, perhaps by promoting neovascularization. Inhibition of PRL expression would limit the production of $16 \mathrm{~K}-\mathrm{PRL}$, a potent antiangiogenic factor. However, the experiments conducted in $\mathrm{GH} 4 \mathrm{C} 1$ cells failed to detect 16K-PRL beyond trace levels. These findings contrast with those detecting 16K-PRL by immunoblotting in the pituitary gland (Shah and Hymer, 1989; Torner et al, 1995) and in pituitary lactotrophs in primary culture (Andries et al, 1992). The reason for this difference is unclear but may relate to the fact that unlike pituitary lactotrophs, which possess dense secretory granules, GH4C1 cells have minimal storage capacity and release PRL rapidly after synthesis (Dannies et al, 1984; Ho et al, 1989). Secretory granules are a possible site for the cleavage of $P R L$ to $16 \mathrm{~K}-\mathrm{PRL}$, because the putative $P R L$-protease, cathepsin-D, is active at acidic $\mathrm{pH}$ values $(<5.5)$ and $\mathrm{PRL}$ granules are acidic (Lorenson et al, 1984). Likewise, because of the acidic $\mathrm{pH}$ requirement, proteolysis of $\mathrm{PRL}$ may not take place extracellularly in normal tissues but can occur in the extracellular milieu of tumors. Low interstitial $\mathrm{pH}$ is a 
well-established pathophysiologic characteristic of solid tumors (Helmlinger et al, 1997; Tannock and Rotin, 1989). On average, tumor $\mathrm{pH}$ ranges from 6.6 to 7.2 (Helmlinger et al, 2002), although the extracellular space within malignant tissues has been measured to be as low as pH 5.8 (Wike-Hooley et al, 1984a, 1984b). In addition, cancerous tissues and cell lines secrete abnormally high levels of the inactive cathepsin-D precursor (procathepsin-D) (Rochefort et al, 2000), and the tumor environment allows for acid-dependent autoactivation of procathepsin-D to yield cathepsin-D and for the catalytic action of the mature enzyme (Conner, 1989; Morikawa et al, 2000). In fact, cathepsin-D secreted by prostate carcinoma cells is responsible for the generation of angiostatin, a potent endogenous inhibitor of angiogenesis that is produced by tumor-mediated proteolysis of plasminogen (Morikawa et al, 2000).

Consistent with the extracellular generation of $16 \mathrm{~K}-$ PRL by PRL-secreting tumor cells, acidification of conditioned medium from $\mathrm{GH} 4 \mathrm{C} 1$ cells resulted in the proteolytic processing of the secreted hormone to a $16-k D a$ product. Because this conversion was inhibited by pepstatin-A, and because both procathepsin-D and mature cathepsin-D were detected in acidified $\mathrm{GH} 4 \mathrm{C} 1$ conditioned medium, these findings indicate that the cells secrete active cathepsin-D able to generate $16 \mathrm{~K}-\mathrm{PRL}$ under acidic conditions. Interestingly, the degree of conversion of $\mathrm{PRL}$ to $16 \mathrm{~K}-\mathrm{PRL}$ was significantly decreased in medium drawn from hypoxic cells, indicating a reduction in secreted cathepsin-D isoforms. Lower levels of both the precursor and the mature protease in hypoxic medium were directly shown by Western blot. When coupled with the decrease in expression of the parent PRL molecule, the suppression of cathepsin-D activity suggests a substantial reduction of 16K-PRL under hypoxic conditions.

In conclusion, our results demonstrate that hypoxia acts in $\mathrm{GH} 4 \mathrm{C} 1$ cells to up-regulate VEGF expression and to down-regulate PRL production and cathepsinD-mediated proteolysis. GH4C1 cells are a clonal strain of rat pituitary tumor cells that have been used extensively to explore mechanisms controlling PRL synthesis and secretion. It would be particularly convenient to extend the present studies in $\mathrm{GH} 4 \mathrm{C} 1$ cells to primary cultures of human PRL tumor cells as a better model of the human neoplastic condition, particularly because there are species differences with respect to $P R L$ that have weakened extrapolations from the rat to the human pituitary. For example rat pituitaries can be exquisitely sensitive to induction of prolactinomas by estrogens, whereas a similar role for estrogens in the etiology of human prolactinomas has not been demonstrated (Horvath and Kovacs, 1994).

Although we hesitate to extend results with a cell line to interpretations concerning tumors, it is useful to consider whether these hypoxia-induced mechanisms might play a role in the development of the human disease. Because pituitary adenomas have limited angiogenic capacity (Jugenburg et al, 1995; Turner et al, 2000a, 2000b; Vidal et al, 2000a), it is conceivable that inhibition of angiogenesis plays a significant role in controlling the dynamics of their progression. Hence, we hypothesize that endocrinologically hyperactive PRL-tumor cells (such as $\mathrm{GH} 3$ cells) would generate more 16K-PRL in the extracellular space due to their high release of $P R L$ and cathepsin $D$ into an acidic microenvironment. The increase in 16K-PRL could be important for maintaining reduced vascularization of prolactinomas. Eventually, such reduction would result in hypoxic areas able to counteract 16K-PRL inhibition by stimulating the expression of VEGF and by decreasing the generation of $16 \mathrm{~K}-\mathrm{PRL}$ via reduced expression of $P R L$ and lower availability of mature cathepsin-D. Although these mechanisms are consistent with the observation that macroprolactinomas are the most vascularized of pituitary adenomas (Turner et al, 2000a), these tumors continue to be less vascularized than the normal tissue (Turner et al, 2000a), indicating that inhibition of angiogenesis is still important and may reflect the action of remaining antiangiogenic factors, including 16K-PRL.

It should be emphasized that tumor angiogenesis depends on the interplay of multiple regulatory factors. Here, we are proposing the interaction of two that are important in the pituitary gland, but it is clear that much more information is needed to form the complete picture of this interaction. For example, 16K-PRL is known to inhibit the angiogenic action of VEGF (Clapp et al, 1993); however, its potency relative to that of VEGF has not been determined, nor its concentration in the pituitary gland adequately measured.

In addition to promoting angiogenesis, hypoxiainduced down-regulation of $\mathrm{PRL}$ and cathepsin-D activity can affect other mechanisms limiting the progression of prolactinomas. PRL can act as an autocrine growth factor within the pituitary itself, because it stimulates the proliferation of $\mathrm{GH} 3$ cells (Krown et al, 1992), and both GH3 cells and normal lactotrophs express PRL receptors (Krown et al, 1992; Morel et al, 1994). In addition, cathepsin-D can promote tumor invasiveness by stimulating cell growth (Glondu et al, 2001; Liaudet et al, 1995), by reducing contact inhibition (Liaudet et al, 1995; Rochefort and LiaudetCoopman, 1999; Rochefort et al, 2000), and by digestion of extracellular matrix components (Briozzo et al, 1988; Heylen et al, 2002). Thus, our findings suggest new pathways contributing to the slow growth and limited invasiveness of prolactinomas and warrant further investigation.

\section{Materials and Methods}

\section{Cell Culture}

GH4C1 cells are a subclone of the cell line GH3 isolated in 1966 from pituitary tumors that had been induced by $\mathrm{x}$-irradiation and found to produce both growth hormone and PRL (Tashjian et al, 1970). The stock line was maintained between passages 3 and 10. GH4C1 cells were cultured in F10 medium (Sigma Chemicals, St. Louis, Missouri) supplemented with $15 \%$ heat-inactivated horse serum (GIBCO, Invitrogen 
Corporation, Carlsbad, California), 2.5\% heatinactivated fetal bovine serum (GIBCO, Invitrogen Corporation), and penicillin-streptomycin at $37^{\circ} \mathrm{C}$ in $5 \% \mathrm{CO}_{2}$. All hypoxia experiments were performed using a standard Plexiglas chamber (Bellco Glass, Vineland, New Jersey) under standard tissue culture conditions for pressure, humidity, and temperature. The chamber was deoxygenated by positive infusion of a $5 \% \mathrm{CO}_{2}-95 \%$ nitrogen gas mixture. During the experiment, $\mathrm{O}_{2} \%$ saturation was maintained at $0.1 \%$ and was continuously monitored with an ambient oxygen sensor (BW Technologies, Arlington, Texas). Subconfluent GH4C1 cell cultures $\left(2 \times 10^{6}\right.$ cells $/ 100$ $\mathrm{mm}$ plates) were plated and incubated in supplemented F10 medium for 12 hours, then incubated in deoxygenated low-serum Opti-MEM I medium (GIBCO, Invitrogen Corporation) supplemented with antibiotics for 12 hours before exposure to hypoxia for 12 to 36 hours. The medium was changed to fresh deoxygenated Opti-MEM I at the beginning of the experiment. Cells under normoxic conditions were treated identically, except that Opti-MEM and the chamber were maintained at normal oxygen concentrations (20\%). At the end of incubation, the number of viable cells was estimated by the dye exclusion method (Harlow and Lane, 1988).

\section{RT-PCR}

Total RNA was isolated using the guanidinium isothiocyanate method (Chomcynski and Sacchi, 1987). RNA $(5 \mu \mathrm{g})$ was reverse transcribed using M-MLV Reverse Transcriptase (Promega, Madison, Wisconsin) and random hexamers (Roche Applied Science, Indianapolis, Indiana). All PCR reactions and primers used for VEGF and the internal control, ribosomal protein L19, were done as described previously (Ochoa et al, 2000). Briefly, PCR reactions were performed using the following primers for VEGF: antisense primer $5^{\prime}-$ GCTCTCTTGGGTGCACTGGA-3' and sense primer 5'-CACCGCCTTGGCTTGTCACA- 3' (Nakamura et al, 1996), with expected sizes of 635,563 , and 431 bp for amplification of VEGF188, VEGF164, and VEGF120, respectively. Primers for the internal control, ribosomal protein L19, were antisense primer 5'CGAAATCGCCAATGCCAACTC-3' and sense primer 5'- TCGTCCATGAGAATCCGCTTG-3', with an expected size of $333 \mathrm{bp}$. The PCR conditions were as follows: denaturation at $95^{\circ} \mathrm{C}$ for 30 seconds, annealing at $65^{\circ} \mathrm{C}$ for 45 seconds, and extension at $72^{\circ} \mathrm{C}$ for 45 seconds, for 28 cycles. PCR products were separated on a $2 \%$ agarose gel, visualized using ethidium bromide, photographed, and analyzed by scanning densitometry.

\section{Northern Blot}

Total RNA was prepared as previously described (Chomcynski and Sacchi, 1987), and $10 \mu \mathrm{g}$ was analyzed by Northern blot as described elsewhere (Sambrook and Russell, 2001). RNA subjected to electrophoresis was transferred to Hybond-N nylon membranes (Millipore, Billerica, Massachusetts), cross-linked, prehybridized at $63^{\circ} \mathrm{C}$ (1 hour), and hybridized (8-12 hours) at $63^{\circ} \mathrm{C}$ with rat $\mathrm{PRL}$ or $\beta$-actin probes. The complete cDNA for rat PRL was used as a probe (generously supplied by R. Maurer, Oregon Health Sciences University, Portland, Oregon). The $\beta$-actin probe was prepared by RT-PCR from rat fibroblasts. The $\beta$-actin primers were the sense primer 5'- ATGGTGGGAATGGGTCAGAA-3' and the antisense primer 5'-TCGTACTCCTGCTTGCTGA-3'. The probes were labeled with $\left[\alpha^{-32} \mathrm{P}\right] \mathrm{dCTP}$ using the random primer procedure (Feinberg and Vogelstein, 1983). Autoradiography followed posthybridization washes. PRL and $\beta$-actin mRNA expression was quantified using scanning densitometry.

\section{GH4 Lysates and Conditioned Media}

After hypoxic exposure, conditioned media were collected, clarified by centrifugation $(1200 \times \mathrm{g} / 10 \mathrm{~min}-$ utes), concentrated 10 times (Centricon 3; Amicon Millipore, Billerica, Massachusetts), and stored at $-70^{\circ} \mathrm{C}$. Cells were lysed in $1 \%$ Nonidet P-40, $0.1 \%$ SDS, $50 \mathrm{~mm}$ Tris, $150 \mathrm{~mm} \mathrm{NaCl}, 1 \mu \mathrm{g} / \mathrm{ml}$ aprotinin, and $100 \mu \mathrm{g} / \mathrm{ml}$ phenylmethylsulfonyl fluoride (Sigma).

\section{Western Blot Analysis}

Eleven micrograms of total protein from GH4C1 cell lysates or $170 \mathrm{ng}$ of protein from conditioned media was mixed with electrophoresis sample buffer containing $\beta$-mercaptoethanol, boiled, and resolved in a $15 \%$ SDS-polyacrylamide gel for PRL analysis and $\beta$-actin, and in a $12 \%$ SDS-polyacrylamide gel for cathepsin-D analysis. Gels were blotted onto nitrocellulose membranes and probed with a 1:1000 dilution of a locally produced anti-PRL antiserum or with 0.8 $\mu \mathrm{g} / \mu \mathrm{l}$ of anti-cathepsin-D polyclonal antibody (Santa Cruz Biotechnology, Inc., Santa Cruz, California). $\beta$-actin was detected by using a 1:250 dilution of a monoclonal anti-actin (mouse ascites fluid, clone AC40; Sigma). The proteins were detected by using enhanced chemiluminescence (SuperSignal West Pico Chemiluminescent Substrate, Pierce Biotechnology, Rockford, Illinois) or the alkaline phosphatase second antibody kit (Bio-Rad Laboratories, Hercules, California). Optical density values were determined using 1D image analysis software v3-5 (Eastman Kodak Company, Rochester, New York).

\section{Silver Staining}

Serum-free conditioned medium drawn from $6.5 \times$ $10^{4}$ GH4C1 cells grown under normoxia or hypoxia was precipitated with trichloroacetic acid. Proteins were subjected to electrophoresis on a reducing $10 \%$ SDS-PAGE. Silver staining was performed according to the method described (Bollag et al, 1996).

\section{ELISA}

ELISA was performed as described elsewhere (Dueñas et al, 1999), using wells coated with $10 \mathrm{ng}$ of 
PRL, a 1:4000 dilution of locally raised anti-PRL antiserum, and a 1:5000 dilution of horseradish peroxidase-conjugated secondary antibodies (Jackson ImmunoResearch Laboratories, Inc., West Grove, Pennsylvania). Bound horseradish peroxidaseconjugated antibodies were revealed by reaction with o-phenylenediamine dihydrochloride in the presence of hydrogen peroxide. Optical density was measured at $490 \mathrm{~nm}$.

\section{PRL Cleavage Analyses}

The activity of the enzymes that cleave PRL to 16KPRL was assayed as described previously (Clapp, 1987) with the following modifications: briefly, $650 \mathrm{ng}$ $(5 \mu l)$ of conditioned media was mixed with $5 \mu$ of 0.1 $\mathrm{M}$ Tris- $\mathrm{HCl}(\mathrm{pH} 7.4)$ and $10 \mu$ l of reaction buffer $(0.1 \mathrm{M}$ citrate-phosphate, $0.15 \mathrm{~m} \mathrm{NaCl}, \mathrm{pH} 5.0$ ) for 24 hours at $37^{\circ} \mathrm{C}$. The final $\mathrm{pH}$ of the reaction mixture was 5.6. The PRL cleavage products were determined by reducing SDS-PAGE and Western blot analyses. Immunoreactive bands were quantified using scanning densitometry.

\section{Statistics}

Results are expressed as mean \pm SE of at least three replicates. Means were compared using either Student's $t$ test or ANOVA followed by Fisher's test for post-hoc comparisons. All PCR and blotting experiments included a control gene or protein that was used to verify identical initial conditions. Because of nonlinearity in signal strength between the experimental and control bands, in some instances the 12-hour normoxia group was used as a baseline to normalize the data. In these instances, the 12-hour normoxia group was not included in the ANOVA, and post-hoc comparisons to this group were made with respect to the normalized mean.

\section{Acknowledgements}

We thank G. Nava, A. Prado, D. Mondragón, M. García, and P. Galarza for their expert technical assistance, and D.D. Pless for editing the manuscript.

\section{References}

Andries M, Tilemans D, and Denef C (1992). Isolation of cleaved prolactin variants that stimulate DNA synthesis in specific cell types in rat pituitary cell aggregates in culture. Biochem J 15:393-400.

Bai HB, Du JZ, and Jia HW (1997). Inhibition effect of hypoxia on humoral immunity of rats. Acta Physiologica Sinica 49: 167-172.

Baldocchi RA, Tan L, King DS, and Nicoll CS (1993). Mass spectrometric analysis of the fragments produced by cleavage and reduction of rat prolactin: Evidence that the cleaving enzyme is cathepsin D. Endocrinology 133:935-938.

Banerjee SK, Sarkar DK, Weston AP, De A, and Campbell DR (1997). Overexpression of vascular endothelial growth factor and its receptor during the development of estrogen-induced rat pituitary tumors may mediate estrogen-initiated tumor angiogenesis. Carcinogenesis 18:1155-1161.

Berchem G, Glondu M, Gleizes M, Brouillet JP, Vignon F, Garcia M, and Liaudet-Coopman E (2002). Cathepsin-D affects multiple tumor progression steps in vivo: Proliferation, angiogenesis and apoptosis. Oncogene 21:5951-5955.

Berk JL, Massoomi N, Hatch C, and Goldstein RH (1999). Hypoxia downregulates tropoelastin gene expression in rat lung fibroblasts by pretranslational mechanisms. Am J Physiol 277:L566-L572.

Bollag DM, Rozycki MD, and Edelstein SJ (1996). Protein methods, 2nd ed. New York: Wiley-Liss, Inc.

Bouissou P, Brisson GR, Peronnet F, Helie R, and Ledoux M (1987). Inhibition of exercise-induced blood prolactin response by acute hypoxia. Can J Sport Sci 12:49-50.

Briozzo P, Morisset M, Capony F, Rougeot C, and Rochefort $\mathrm{H}$ (1988). In vitro degradation of extracellular matrix with $\mathrm{Mr}$ 52,000 cathepsin D secreted by breast cancer cells. Cancer Res 48:3688-3692.

Brizel DM, Scully SP, Harrelson JM, Layfield LJ, Bean JM, Prosnitz LR, and Dewhirst MW (1996). Tumor oxygenation predicts for the likelihood of distant metastases in human soft tissue sarcoma. Cancer Res 36:941-943.

Bunn HF and Poyton RO (1996). Oxygen sensing and molecular adaptation to hypoxia (Review). Physiol Rev 76:839885.

Chen Z and Du JZ (1996). Hypoxia effects on hypothalamic corticotropin-releasing hormone and anterior pituitary cAMP. Zhongguo Yao Li Xue Bao 17:489-492.

Chomcynski P and Sacchi N (1987). Single-step method of RNA isolation by acid guanidinium thiocyanate-phenolchloroform extraction. Anal Biochem 12:156-159.

Clapp C (1987). Analysis of the proteolytic cleavage of prolactin by the mammary gland and liver of the rat: Characterization of the cleaved and $16 \mathrm{~K}$ forms. Endocrinology 121:2055-2064.

Clapp C, Martial JA, Guzman RC, Rentier-Delure F, and Weiner RI (1993). The 16-kilodalton N-terminal fragment of human prolactin is a potent inhibitor of angiogenesis. Endocrinology 133:1292-1299.

Conner GE (1989). Isolation of procathepsin D from mature cathepsin $\mathrm{D}$ by pepstatin affinity chromatography: Autocatalytic proteolysis of the zymogen form of the enzyme. Biochem J 263:601-604.

Corbacho AM, Martinez de la Escalera G, and Clapp C (2002). Roles of prolactin and related members of the prolactin/growth hormone/placental lactogen family in angiogenesis (Review). J Endocrinol 173:219-238.

Cunnah D and Besser M (1991). Management of prolactinomas. Clin Endocrinol (Oxf) 34:231-235.

Czyzyk-krzeska MF, Furnari BA, Lawson EE, and Millhorn DE (1994). Hypoxia increases rate of transcription and stability of tyrosine hydroxylase mRNA in pheochromocytoma (PC12) cells. J Biol Chem 269:760-764.

Dannies PS, Kiino DR, and Amara JF (1984). Estrogen effects on prolactin storage and cell growth in GH cells. In: Mena $F$ and Valverde-RC, editors. Prolactin secretion: A multidisciplinary approach. Orlando: Academic Press, 121-140. 
Du JZ and Li QF (1982). Effects of simulated hypoxia acclimation on organism, organ and hematology in Ochotona curzoniae and rats. Acta Theriologica Sinica 2:35-42.

Dueñas Z, Torner L, Corbacho AM, Ochoa A, GutierrezOspina G, Lopez-Barrera F, Barrios FA, Berger P, Martinez de la Escalera G, and Clapp C (1999). Inhibition of rat corneal angiogenesis by $16-\mathrm{kDa}$ prolactin and by endogenous prolactin-like molecules. Invest Ophthalmol Vis Sci 40:24982505.

Enholm B, Paavonen K, Ristimaki A, Kumar V, Gunji Y, Klefstrom J, Kivinen L, Laiho M, Olofsson B, Joukov V, Eriksson U, and Alitalo K (1997). Comparison of VEGF, VEGF-B, VEGF-C and Ang-1 mRNA regulation by serum, growth factors, oncoproteins and hypoxia. Oncogene 14: 2475-2483.

Feinberg AP and Vogelstein B (1983). A technique for radiolabeling DNA restriction endonuclease fragments to high specific activity. Anal Biochem 132:6-13.

Folkman $J$ (1990). What is the evidence that tumors are angiogenesis dependent? J Natl Cancer Inst 82:4-6.

Glondu M, Coopman P, Laurent-Matha V, Garcia M, Rochefort $H$, and Liaudet-Coopman E (2001). A mutated cathepsin-D devoid of its catalytic activity stimulates the growth of cancer cells. Oncogene 20:6920-6929.

Graeber TG, Osmanian C, Jacks T, Housman DE, Koch CJ, Lowe SW, and Giaccia AJ (1996). Hypoxia-mediated selection of cells with diminished apoptotic potential in solid tumours. Nature 379:88-91.

Harlow E and Lane D (1988). Antibodies: A laboratory manual. New York: Cold Spring Harbor Laboratory, 256.

Helmlinger G, Sckell A, Dellian M, Forbes NS, and Jain RK (2002). Acid production in glycolysis-impaired tumors provides new insights into tumor metabolism. Clin Cancer Res 8:1284-1291.

Helmlinger G, Yuan F, Dellian M, and Jain RK (1997). Interstitial $\mathrm{pH}$ and $\mathrm{pO}_{2}$ gradients in solid tumors in vivo: Highresolution measurements reveal a lack of correlation. Nat Med 3:177-182.

Heylen N, Vincent LM, Devos V, Dubois V, Remacle C, and Trouet A (2002). Fibroblasts capture cathepsin D secreted by breast cancer cells: Possible role in the regulation of the invasive process. Int J Oncol 20:761-767.

Ho TW, Greenan JR, and Walker AM (1989). Mammotroph autoregulation: The differential roles of the $24 \mathrm{~K}$ isoforms of prolactin. Endocrinology 124:1507-1514.

Hochachka PW, Buck LT, Doll CJ, and Land SC (1996). Unifying theory of hypoxia tolerance: Molecular/metabolic defense and rescue mechanisms for surviving oxygen lack. Proc Natl Acad Sci USA 93:9493-9498.

Hockel M and Vaupel P (2001). Tumor hypoxia: Definitions and current clinical, biologic, and molecular aspects (Review). J Natl Cancer Inst 93:266-276.

Horvath E and Kovacs K (1994). Morphology of adenohypophyseal cells and pituitary adenomas. In: Imura $\mathrm{H}$, editor. The pituitary gland, 2nd ed. New York: Raven Press, 29-62.

Jugenburg M, Kovacs K, Stefaneanu L, and Scheithauer BW (1995). Vasculature in nontumorous hypophyses, pituitary adenomas and carcinomas: A quantitative morphologic study. Endocr Pathol 6:115-124.
Krown KA, Wang YF, Ho TW, Kelly PA, and Walker AM (1992). Prolactin isoform 2 as an autocrine growth factor for GH3 cells. Endocrinology 131:595-602.

Lee H, Struman I, Clapp C, Martial J, and Weiner RI (1998). Inhibition of urokinase activity by the antiangiogenic factor 16K prolactin: Activation of plasminogen activator inhibitor 1 expression. Endocrinology 139:3696-3703.

Liaudet E, Derocq D, Rochefort H, and Garcia M (1995). Transfected cathepsin D stimulates high density cancer cell growth by inactivating secreted growth inhibitors. Cell Growth Differ 6:1045-1052.

Lohrer P, Gloddek J, Hopfner U, Losa M, Uhl E, Pagotto U, Stalla GK, and Renner U (2001). Vascular endothelial growth factor production and regulation in rodent and human pituitary tumor cells in vitro. Neuroendocrinology 74:95-105.

Lorenson MY, Miska SP, and Lacobs LS (1984). Molecular mechanism of prolactin release from pituitary secretory granules. In: Mena F and Valverde-RC, editors. Prolactin secretion: A multidisciplinary approach. Orlando: Academic Press, 141-160.

Lou Y, Oberpriller JC, and Carlson EC (1997). Effect of hypoxia on the proliferation of retinal microvessel endothelial cells in culture. Anat Rec 248:366-273.

Martini JF, Piot C, Humeau LM, Struman I, Martial JA, and Weiner RI (2000). The antiangiogenic factor 16K PRL induces programmed cell death in endothelial cells by caspase activation. Mol Endocrinol 14:1536-1549.

Minchenko A, Bauer T, Salceda S, and Caro J (1994). Hypoxic stimulation of vascular endothelial growth factor expression in vitro and in vivo. Lab Invest 71:374-379.

Morel G, Ouhtit A, and Kelly PA (1994). Prolactin receptor immunoreactivity in rat anterior pituitary. Neuroendocrinology 59:78-84.

Morikawa W, Yamamoto K, Ishikawa S, Takemoto S, Ono M, Fukushi J, Naito S, Nozaki C, Iwanaga S, and Kuwano M (2000). Angiostatin generation by cathepsin D secreted by human prostate carcinoma cells. J Biol Chem 275:3891238920.

Moromisato DY, Moromisato MY, Brasel JA, and Cooper DM (1999). Effect of growth hormone therapy in mitigating hypoxia-induced and food restriction-induced growth retardation in the newborn rat. Crit Care Med 27:2234-2238.

Nakamura Y, Morishita R, Higaki J, Kida I, Aoki M, Moriguchi A, Yamada K, Hayashi S, Yo Y, Nakano H, Matsumoto K, Nakamura T, and Ogihara T (1996). Hepatocyte growth factor is a novel member of the endothelium-specific growth factors: Additive stimulatory effect of hepatocyte growth factor with basic fibroblast growth factor but not with vascular endothelial growth factor. J Hypertens 14:1067-1072.

Niinikoski J, Hunt TK, and Dunphy JE (1972). Oxygen supply in healing tissue. Am J Surg 123:247-252.

Ochoa AL, Mitchner NA, Paynter CD, Morris RE, and BenJonathan N (2000). Vascular endothelial growth factor in the rat pituitary: Differential distribution and regulation by estrogen. J Endocrinol 165:483-492.

Pellegrini I, Gunz G, Ronin C, Fenouillet E, Peyrat JP, Delori $P$, and Jaquet $P$ (1988). Polymorphism of prolactin secreted by human prolactinoma cells: Immunological, receptor binding, and biological properties of the glycosylated and nonglycosylated forms. Endocrinology 122:2667-2674. 
Richard DE, Berra E, and Pouyssegur J (1999). Angiogenesis: How a tumor adapts to hypoxia. Biochem Biophys Res Commun 266:718-722.

Rochefort H, Capony F, and Garcia M (1990). Cathepsin D in breast cancer: From molecular and cellular biology to clinical applications. Cancer Cells 2:383-388.

Rochefort H, Garcia M, Glondu M, Laurent V, Liaudet E, Rey JM, and Roger P (2000). Cathepsin D in breast cancer: Mechanisms and clinical applications, a 1999 overview. Clin Chim Acta 291:157-170.

Rochefort H and Liaudet-Coopman E (1999). Cathepsin D in cancer metastasis: A protease and a ligand. APMIS 107:8695.

Sambrook J and Russell DW (2001). Molecular cloning: A laboratory manual, 3rd ed. New York: Cold Spring Harbor Laboratory.

Schechter J (1972). Ultrastructural changes in the capillary bed of human pituitary tumors. Am J Pathol 67:109-126.

Shah GN and Hymer WC (1989) Prolactin variants in the rat adenohypophyses. Mol Cell Endocrinol 61:97-107.

Shweiki D, Itin A, Soffer D, and Keshet E (1992). Vascular endothelial growth factor induced by hypoxia may mediate hypoxia-initiated angiogenesis. Nature 359:843-845.

Sinha YN and Gilligan TA (1984). A cleaved form of prolactin in the mouse pituitary gland: Identification and comparison of in vitro synthesis and release in strains with high and low incidences of mammary tumors. Endocrinology 114:20462053.

Sinha YN, Gilligan TA, Lee DW, Hollingsworth D, and Markoff E (1985). Cleaved prolactin: Evidence for its occurrence in human pituitary gland and plasma. J Clin Endocrinol Metab 60:239-243.

Stubbs M, McSheehy PM, Griffiths JR, and Bashford CL (2000). Causes and consequences of tumour acidity and implications for treatment. Mol Med Today 6:15-19.

Tannock IF and Rotin D (1989). Acid pH in tumors and its potential for therapeutic exploitation. Cancer Res 49:43734384.

Tashjian AH Jr, Bancroft FC, and Levine L (1970). Production of both prolactin and growth hormone by clonal strains of rat pituitary tumor cells: Differential effects of hydrocortisone and tissue extracts. J Cell Biol 47:61-70.
Tenan M, Fulci G, Albertoni M, Diserens AC, Hamou MF, El Atifi-Borel M, Feige JJ, Pepper MS, and Van Meir EG (2000). Thrombospondin-1 is downregulated by anoxia and suppresses tumorigenicity of human glioblastoma cells. J Exp Med 191:1789-1798.

Torner L, Mejia S, Lopez-Gomez FJ, Quintanar A, Martinez de la Escalera G, and Clapp C (1995). A 14-kilodalton prolactin-like fragment is secreted by the hypothalamoneurohypophyseal system of the rat. Endocrinology 136: 5454-5460.

Turner HE, Nagy Z, Gatter KC, Esiri MM, Harris AL, and Wass JA (2000a). Angiogenesis in pituitary adenomas and the normal pituitary gland. J Clin Endocrinol Metab 85:11591162.

Turner HE, Nagy Z, Gatter KC, Esiri MM, Harris AL, and Wass JA (2000b). Angiogenesis in pituitary adenomas: Relationship to endocrine function, treatment and outcome. J Endocrinol 165:475-481.

Vidal S, Oliveira MC, Kovacs K, Scheithauer BW, and Lloyd R (2000a). Immunolocalization of vascular endothelial growth factor in the GH3 cell line. Cell Tissue Res 300:83-88.

Vidal S, Scheithauer BW, and Kovacs K (2000b). Vascularity in nontumorous human pituitaries and incidental microadenomas: A morphometric study. Endocr Pathol 11: 215-227.

Warner MD, Sinha YN, and Peabody CA (1993). Growth hormone and prolactin variants in normal subjects: Relative proportions in morning and afternoon samples. Horm Metab Res 25:425-429.

Wike-Hooley JL, Haveman J, and Reinhold HS (1984a). The relevance of tumour $\mathrm{pH}$ to the treatment of malignant disease. Radiother Oncol 2:343-366.

Wike-Hooley JL, Van der Zee J, van Rhoon GC, Van den Berg AP, and Reinhold HS (1984b). Human tumour pH changes following hyperthermia and radiation therapy. Eur $\mathrm{J}$ Cancer Clin Oncol 20:619-623.

Yang SM, Du JZ, and Li LC (1995). Effect of hypoxia on the development of hypothalamic corticotropin-releasing factor of neonatal rats. Chin J Appl Physiol 12:294-297.

Zhang YS and Du JZ (2000). The response of growth hormone and prolactin of rats to hypoxia. Neurosci Lett 279: $137-140$ 